УДК 616.379-008.64

\title{
ПОВЫШЕНИЕ ЭФФЕКТИВНОСТИ ФЛУОРЕСЦЕНТНОЙ ДИАГНОСТИКИ ПРИ ИСПОЛЬЗОВАНИИ БИОСЕНСОРА ГЛЮКОЗЫ С СОДЕРЖАНИЕМ ПОЛИ-2-ГИДРОКСИЭТИЛМЕТАКРИЛАТА В СОВРЕМЕННОЙ ДИАБЕТОЛОГИИ
}

\begin{abstract}
Минаков Григорий Игоревич
инженер-технолог

Научный руководитель: Мороз Игорь Александрович

зам. директора по производству

Производственное унитарное предприятие «ФреБор»
\end{abstract}

\begin{abstract}
Аннотация: Учитывая неуклонный рост заболеваемости сахарным диабетом, как 1-го, так и 2-го типа среди взрослых и детей, разработка современных средств непрерывного мониторирования глюкозы для проведения самоконтроля с целью улучшения компенсации углеводного обмена, профилактики развития и прогрессирования осложнений, к которым относится подкожный датчик глюкозы, разрабатываемый на Унитарном предприятии «ФреБор» является актуальным, современным и перспективным направлением современной диабетологии.
\end{abstract}

Ключевые слова: Медицинские науки, технологии, диабетология, углеводный обмен, глюкометр, биосенсор, подкожный датчик глюкозы, флуоресценция, химический состав, поли-2-гидроксиэтилметакрилат.

\section{THE INCREASE OF THE FLUORESCENCE DIAGNOSTICS EFFICIENCY WHEN USING A GLUCOSE BIOSENSOR CONTAINING POLY 2- HYDROXYETHYL METHACRYLATE IN THE PRESENT-DAY DIABETOLOGY}

\section{Minakov Grigory Igorevich Moroz Igor Alexandrovich}

\begin{abstract}
Taking in account the steady growth of diabetes mellitus, both type 1 and type 2, among adults and children, the development of devices for continuous glucose monitoring for self-check in order to improve the carbohydrate metabolism,
\end{abstract}


to prevent the development and progression of complications (the subcutaneous glucose sensor belongs to such devices and is being designed at the Unitary enterprise "FreBor") is an actual, current and upcoming trend of present-day diabetology.

Key word: Medical sciences, technology, diabetology, carbohydrate metabolism, glucometer, biosensor, subcutaneous glucose sensor, fluorescence, chemical composition, poly-2-hydroxyethyl methacrylate.

Сахарный диабет является очень серьезным заболеванием. Из-за большого количества людей, больных сахарным диабетом, данное заболевание можно отнести к пандемии неинфекционного характера XXI века.

Сахарный диабет характеризуется нарушением секреции инсулина и той или иной степенью инсулинорезистентности, обусловливающими гипергликемию. Ранние симптомы связаны с гипергликемией и включают полидипсию, полифагию, полиурию и сужение полей зрения. К поздним осложнениям относятся ангиопатии, периферическая нейропатия, нефропатия и предрасположенность к инфекционным заболеваниям. Диагноз устанавливают на основании результатов измерения уровня глюкозы в плазме. Лечение включает диету, физические нагрузки и применение средств, снижающих уровень глюкозы (инсулина и пероральных сахароснижающих препаратов). Осложнения можно отсрочить или предотвратить надлежащим контролем гликемии; основной причиной смертности при сахарном диабете остается поражение сердца [1].

С целью снижения риска осложнений при сахарном диабете используются различные медицинские устройства, к примеру - глюкометры.

Глюкометр - прибор для измерения уровня глюкозы в органических жидкостях (кровь, ликвор и т.п.).

Существует несколько методик измерения. В последнее время получили широкое распространение портативные глюкометры для проведения измерений в домашних условиях. Достаточно нанести каплю крови на одноразовую индикаторную пластину, установленную в глюкозоксидазный биосенсор, и через несколько секунд концентрация уровня глюкозы в крови (гликемия) известна. Для разных лабораторий, методик и аппаратов нормы гликемии различны, для глюкозоксидантного метода - 3,33-5,55 ммоль. 
Глюкометры имеют ряд недостатков: болезненные ощущения при заборе крови, присутствует риск заражения крови, нет возможности связать глюкометр с телефоном или компьютером и другие.

С целью улучшения компенсации углеводного обмена, профилактики развития и прогрессирования осложнений на Производственном унитарном предприятии «ФреБор» разрабатывается подкожный датчик глюкозы. В свою очередь данное устройство позволит улучшить метод измерений глюкозы в крови снижая риски заражения крови, избавиться от болезненных ощущений и осуществлять постоянный мониторинг глюкозы.

Подкожный датчик глюкозы (флуоресцентный биосенсор глюкозы) устройство, измеряющие концентрацию глюкозы с помощью индикаторного гидрогеля с содержанием флюорофора [2].

Подкожный датчик глюкозы является отличной альтернативой по замене глюкометров, так имеют ряд преимуществ над ними.

Подкожный датчик глюкозы представляет из себя два конструктивных элемента: микрокапсула из полимерных материалов с содержанием индикаторного гидрогеля и передатчик, выполняющий роль передачи данных на дисплей смартфона или любого устройства, обладающего технологией Bluetooth.

Разработка медицинского устройства, позволяющего контролировать уровень глюкозы в крови больного сахарным диабетом в любой момент времени и своевременно и оперативно реагировать на колебания уровня глюкозы - является ключевой задачей в оптимизации метода измерения глюкозы.

Основным химических веществом индикаторного гидрогеля является поли-2-гидроксиэтилметакрилат.

Поли-2-гидроксиэтилметакрилат - известный биосовместимый полимер. Гели на его основе, ограничено набухающие в воде и физиологических растворах, применяются в качестве материала для изготовления мягких контактных линз, имплантатов, в реконструктивной хирургии, также в составе композитов.

Поли-2-гидроксиэтилметакрилат используют в медицине и медицинской промышленности, а именно, при получении материалов для изготовления протезов различных органов.

Сшитый, нерастворимый поли-(2-гидроксиметилакрилат), получают путем полимеризации 2-гидроксиэтилметакрилата в присутствии катализатора 
- перхлората пента (диметилсульфоксид) ванадила в количестве 0,004-0,1 мас. \% от реакционной массы.

Современным методом получения 2-гидроксиэтилметакрилата является реакция взаимодействия окиси этилена с 2-метил-2-пропеновой кислотой (метакриловая кислота).

Методика синтеза 2-гидроксиэтилметакрилата может быть осуществлена нагреванием 2-метил-2-пропеновой кислоты с окисью этилена в присутствии хлорида железа (III) или трис-(2-хлорэтилат) железа с использованием бензола и 1-азациклогекса-1,3,5-триена или с использованием метилата натрия (рис. 1.) [3].<smiles>C=C(C)C(=O)O</smiles>

Метакриловая кислота

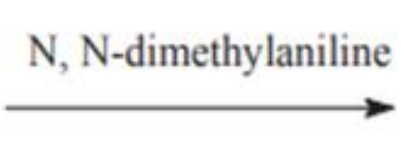

Этиленоксид

\section{Рис. 1. Схема промышленного синтеза 2-гидроксиэтилметакрилата}

Синтезированный 2-гидроксиэтилметакрилата может быть подвергнут объемной радикальной гомополимеризации для получения полимера с целью изготовления индикаторного гидрогеля для подкожного датчика глюкозы.

В качестве катализатора можно использовать пероксид водорода, так как он легко разлагается и превращается в воду после каталитических процессов инициатора каталитической реакции (рис. 2.) [3]. 
n<smiles>C=C(C)C(=O)OCCO</smiles>

2-Гидроксиэтилметакрилат

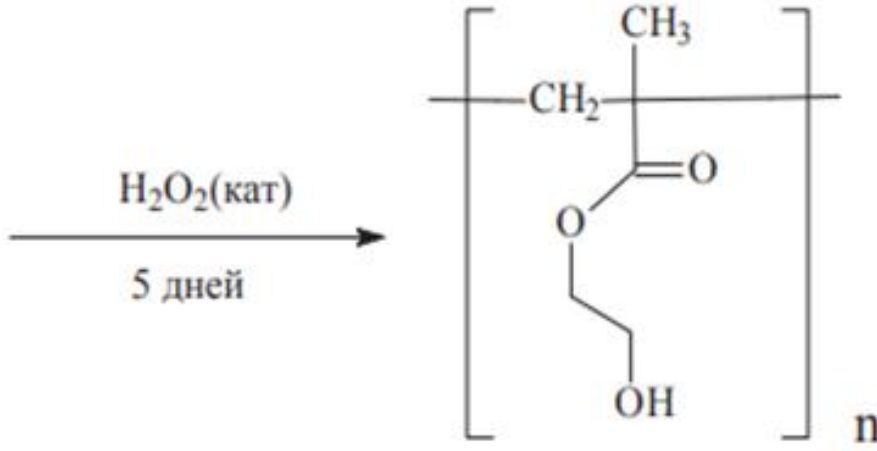

Поли-2-гидроксиэтилметакрилат

Рис. 2. Получение поли-2-гидроксиэтилметакрилата

Тем самым в данной статье были рассмотрены вопросы химического состава индикаторного гидрогеля для создания подкожного датчика глюкозы, рассмотрена задача повышения эффективности флуоресцентной диагностики в современной диабетологии, показан промышленный метод получения 2гидроксиэтилметакрилат с последующей реакцией полимеризации. На основании всего рассмотренного можно сделать следующие выводы.

Выводы. Улучшение прогноза пациентов, страдающих диабетом 2 типа, в высокой степени определяется адекватным контролем всех параметров гликемии (коррекция гипер- и гипогликемии, нормализация вариабельности гликемии). Для полноценной идентификации и своевременной коррекции всех отклонений уровня гликемии чрезвычайно важен еe самоконтроль. Используемые в настоящее время для самоконтроля методы имеют ряд существенных недостатков, ограничивающих их использование. Наиболее значимые проблемы существующих методов самоконтроля включают недостаточную точность, инвазивность, высокую стоимость, что приводит к отсутствию должной частоты измерения уровня гликемии и, соответственно, вносит трудности в компенсацию сахарного диабета. Эти факторы определяют необходимость создания неинвазивных, рентабельных и высокоточных методов оценки гликемии. Для неинвазивного определения уровня глюкозы предложено большое количество различных подходов, начиная от оптических методов анализа, заканчивая ультразвуковыми и биоимпедансными методиками.

Проанализированная научно-методическая литература и обобщенный личный опыт в производстве медицинских устройств и изделий позволяют сделать следующие выводы: 
1. Сахарный диабет является тяжелым соматическим заболеванием, при котором и в настоящее время сохраняется высокая инвалидизация и смертность больных, связанная с развитием диабетических осложнений.

2. Использование подкожного датчика для определения уровня глюкозы в крови больных сахарным диабетом позволит оптимизировать процесс постоянного контроля глюкозы, значительно улучшить качество жизни больных сахарным диабетом и исключить неприятные ощущения в области нервных окончаний области пункции.

3. Все используемые материалы являются биосовместимыми.

\section{Список литературы}

1. Сахарный диабет и нарушения углеводного обмена / Справочник MSD [Электронный ресурс] - Дата обращения: 27.01.2021 г.

2. Анциферов М.Б. Старостина Е.Г. Галстян Г.Р. Самоконтроль и обучение больных как основа эффективного лечения сахарного диабета // Актуальные вопросы клинической диабетологии. Научные труды, том 3., Казань. - 1994.- с.102-104.

3. Бачериков В.А. 2-гидроксиэтилметакрилат и применение полимерных материалов на его основе // Международный гуманитарный университет. Научные труды, № 18. 2013 г. - с.264-266.

4. Muñoz-Berbel X., Godino N., Laczka O., Baldrich E., Xavier M.F., Javier D.C.F. ImpedanceBased Biosensors for Pathogen Detection. In: Principles of Bacterial Detection: Biosensors, Recognition Receptors and Microsystems / Zourob M., Elwary S., Turner A., Eds; Springer, New York, 2008. - P. 341-370.

5. Lim J.W., Ha D., Lee J., Lee S.K., Kim T. Review of micro/ nanotechnologies for microbial biosensors. // Front. Bioeng. Biotechnol. 2015. 3:61.

(С Г.И. Минаков, И.А. Мороз, 2021 